\title{
Cutaneous calcinosis induced by intravenous calcium gluconate administration
}

\section{Anissa Zaouak, Leila Bouhajja, Houda Hammami, Samy Fenniche}

\author{
Department of Dermatology, Habib Thameur Hospital, Tunis, Tunisia
}

Corresponding author: Anissa Zaouak, MD, E-mail: anissa_zaouak@yahoo.fr

A 78-year-old woman presented to our dermatology department for an indurated plaque on her right wrist since three weeks. There was a history of confusion due to hypocalcemia for which the patient received intravenous injections of calcium gluconate. Calcium gluconate solution was administered through a peripheral vein. An episode of extravasation occurred involving her right wrist causing skin erythema, oedema, pain and cutaneous ulceration. Two weeks later, the erythematous plaque which appeared on her wrist gradually became indurated. Dermatologic examination revealed an indurated plaque measuring $32 \mathrm{~mm} \times 35 \mathrm{~mm}$ in size located on her right wrist on an overlying erythematous skin (Fig. 1). Cultures were negative for microorganisms. The patient had normal blood analysis including serum calcemia and serum phosphate. A skin biopsy was performed revealing calcium deposition in the dermis. The diagnosis of iatrogenic cutaneous calcinosis due to local tissue injury was assessed. The patient was treated with emollients and keratolytics and the plaque healed progressively leaving an atrophic scar.

Iatrogenic calcinosis cutis is an uncommon complication of the administration of intravenous calcium containing solutions [1]. According to Watanabe et al [2], about 18 cases of calcinosis cutis after intravenous administration of calcium preparations have been reported in the literature. Herein we report a new case of iatrogenic cutaneous calcinosis in an old woman. The precise pathogenesis underlying the development of iatrogenic calcinosis cutis is not well understood. This complication could occur with or without extravasation of calcium. In fact, even minor extravasation of calcium containing solutions can produce lesions of calcinosis cutis.
After extravasation of a calcium containing solution, cutaneous lesions typically develop within 2 weeks. Watanabe et al [2] proposed an explanation to this phenomenon. In fact, it appears according to this author that the introduction of the needle causes tissue injury with capillary disruption in the dermis. In our case, it is iatrogenic due mainly to skin deposits of calcium which cause tissue damage.

Extravasation of calcium solutions may induce a marked inflammatory reaction with soft tissue necrosis and cutaneous calcification. However, extravasation is not a prerequisite for tissue calcification. Alkalinity also favours precipitation of calcium salts [3]. Calcification is defined by the deposition of insoluble calcium salts in the dermis. This deposition leads to a transient increase in calcium concentration in the extracellular matrix between collagen fibers with subsequent binding of calcium phosphate in the dermis and deposition of calcium phosphate crystals in the dermis.

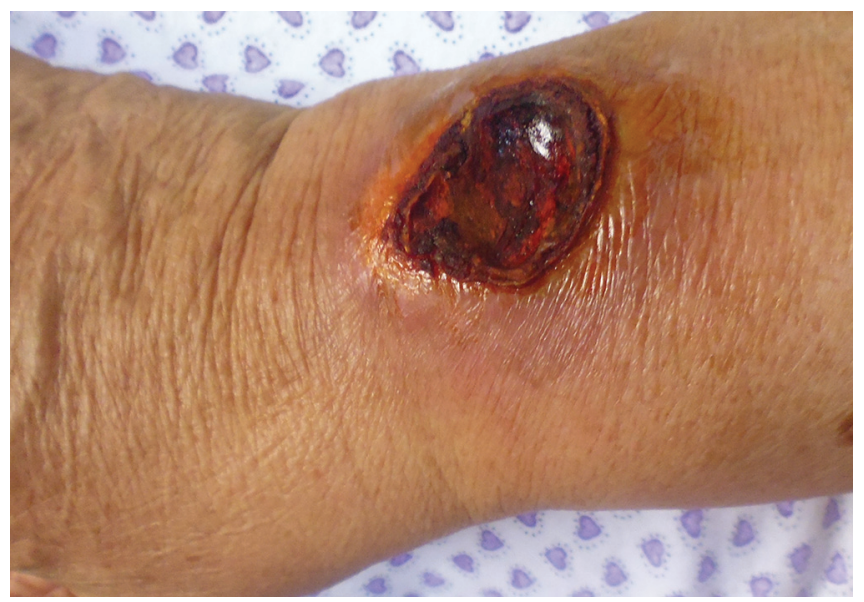

Figure 1: Indurated plaque measuring $32 \mathrm{~mm} \times 35 \mathrm{~mm}$ in size located on the right wrist on an overlying erythematous skin.

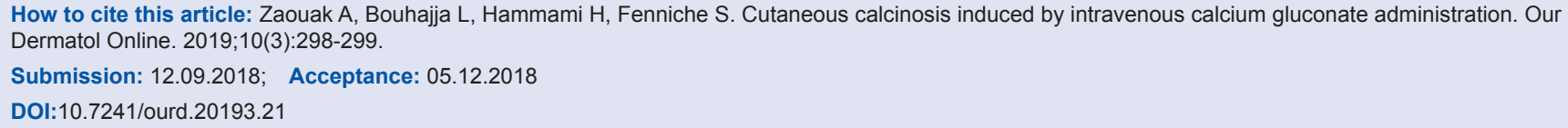


This iatrogenic calcinosis cutis should be differentiated from metastatic, dystrophic and idiopathic causes of this calcinosis cutis. In fact, metastatic calcification occurs in undamaged tissue and is associated with elevated serum calcium levels. Idiopathic calcification occurs in the absence of evident tissue or metabolic abnormalities. Dystrophic calcification occurs as a result of local tissue injuries or abnormalities [1].

This case is being reported to highlight this possible complication of intravenous calcium administration. A careful medical history taking is important to recognize this complication.

\section{Consent}

The examination of the patient was conducted according to the Declaration of Helsinki principles.

\section{REFERENCES}

1. Ankad BS, Miskin AT, Math MK, Sakhare PS. Calcinosis cutis mimicking xanthoma: A case report. 2018;9:95-6.

2. Watanabe S, Shioda T, Kobayashi K, Ishizaki S, Ito F, Fujibayashi M, et al. Calcinosis cutis confined to the dermis after intravenous administration of a calcium preparation: a case report and review of the Japanese literature. Case Rep Dermatol. 2014;6:85-90.

3. Rodríguez L, Di Martino Ortiz B, Contreras R, Rodriguez Masi M, Knopfelmacher O, Bolla de Lezcano L. Metastatic calcinosis cutis: calciphylaxis (calcified uremic arteriolopathy). A case report. Our Dermatol Online. 2013;4:358-60.

Copyright by Anissa Zaouak, et al. This is an open-access article distributed under the terms of the Creative Commons Attribution License, which permits unrestricted use, distribution, and reproduction in any medium, provided the original author and source are credited.

Source of Support: Nil, Conflict of Interest: None declared. 